\title{
Miscellany
}

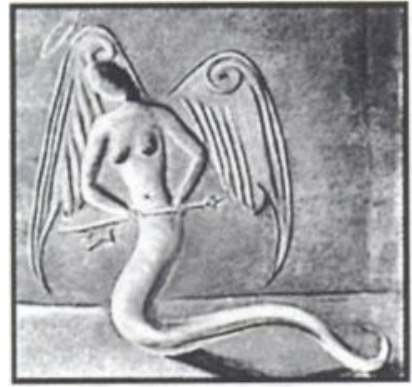

\section{The Ball of Angels}

The Zito Trust is hosting a Christmas Ball, called The Ball of Angels, on Saturday 2nd December 1995. The Ball will take place at the World Trade Centre, St Katherine's Dock, London E1. Tickets cost $£ 55$ (or $£ 500$ for a table of 10), to include: Champagne Reception, Four Course Dinner and Wine. With a variety of VIP guests and top class entertainment. the evening promises to be enjoyable and good value.

The Zito Trust was established by Jayne Zito following the death of her husband. His death was the cause of the Inquiry into the Care and Treatment of Christopher Clunis. Dr Flona Caldicott is a patron of the Trust.

The aim of the Trust is to provide a comprehensive network of support for the 'victims' of the fallures of community care. By the term 'victims' it is meant the families, relatives and carers of sufferers, the professionals who work with severely mentally ill, and members of the public who contact the Trust with a diverse range of concerns.

The range of services provided includes: representation and support during legal proceedings and inquiries; information and advice concerning the implementation of policy at both government and local levels.

All proceeds and donations will directly finance the Zito Trust's victim support service.
Further information: Gary Robjent. The Royal College of Psychiatrists (telephone: 0171235 2351 ext 169).

The Mental Health Foundation charity is launching an Inquiry into Commonity Eervices and Opportunities for People with Learning Disabilities as a response to concern over the severe lack of awareness of, and resources for, this group of people. It will aim to influence government policy and action on a national and local level.

The Inquiry, which will be chaired by Dame Gillian Wagner, will identify what resources need to be made available for adults with learning disablitiles to enable them to live as full and independent lives in the community as possible. It will inform policy makers and practitioners, purchasers and providers and people with learning disabilities and their carers. Information will enable professionals to plan services proactively instead of reactively responding to unmet needs, thereby improving standards and increasing choice.

The Inquiry will be the first to involve senior figures from the health, social services and housing fields and to be steered by a user-led organisation, CHANGE.

Further information: Antoinette Dale Roberts or Flona Fountain in the Press Office on 0171580 0145, Flona Fountain (mobile) 0585246 623.

\section{New publications}

The Care Guide: A handbook for the caring profession and other agencies edited by Michael Jacobs is now available from Cassell of Wellington House, 125 Strand, London WC2R OBB.

Direct Power by Alan Leader is jointly published by Pavilion Publishing and the Community Support Network. Brixton Community Sanctuary and MIND and is available from Pavilion Publishing, 8 St George's Place, Brighton, BN1 4GB. 